\title{
Morfologia dos órgãos genitais masculinos do punaré (Thrichomys laurentius $)^{1}$
}

\author{
Willian Xavier Figueredo ${ }^{2}$, Ricardo Romão Guerra ${ }^{3}$, Lucas Rannier Ribeiro Antonino Carvalho ${ }^{4}$, \\ Helder Camilo da Silva Pereira ${ }^{5}$, Moacir Franco de Oliveira ${ }^{6}$
}

\begin{abstract}
Resumo: O punaré é um pequeno roedor de hábitos diurnos e noturnos, habitando principalmente áreas rochosas. Neste estudo objetivou-se estudar macroscopicamente e microscopicamente o aparelho genital masculino do punaré. Os animais foram eutanasiados sendo então realizadas as coleta de testículos e demais estruturas genitais. Os testículos apresentaram túbulos seminíferos com as células da linhagem espermática e de Sertoli. O epidídimo apresentou seus túbulos compostos por um epitélio pseudoestratificado com estereocílios, composto por células basais e prismáticas. $\mathrm{O}$ ducto deferente apresentou mucosa pregueada formada por um tecido epitelial prismático simples, onde observou-se duas camadas de músculo liso, uma interna circular e uma externa longitudinal, podendo-se observar ainda uma adventícia composta de tecido conjuntivo denso nãomodelado. A próstata possuiu um parênquima que pode ser dividido em duas regiões; uma com alvéolos glandulares apoiados em grande quantidade de musculo liso, e outra com alvéolos glandulares circundados com menor quantidade de músculo liso, sendo apoiado em um tecido conjuntivo denso não-modelado. A glândula vesicular possuiu uma mucosa composta por um epitélio cúbico simples sendo formada por túbulos que podem ser retos ou tortuosos com secreção presente no interior do lúmen tubular. Concluímos que os órgãos genitais masculinos do punaré são semelhantes macroscopicamente aos órgãos dos roedores de forma geral, havendo microscopicamente algumas diferenças entre outras espécies de roedores.
\end{abstract}

Palavras-chave: Roedor; Aparelho genital masculino; Anatomia; Histologia.

\section{Morphology of the male genital of Thrichomys laurentius "Thomas, 1904"}

\begin{abstract}
The punare is a small rodent of day and night habits, inhabiting mainly rocky areas. In this work the structures of the male genital apparatus of the punare were studied macroscopically and microscopically. The animals were sacrificed following the bioethical recommendations, where the testicles and other genital structures were collected. The testicles had seminiferous tubules with cells of the spermatic line and Sertoli cells. The epididymis presented its tubules composed of a pseudostratified epithelium with stereocylls, composed of basal and cylindrical cells. The deferents duct presented a pleated mucosa formed by a simple cylindrical epithelial tissue, where two layers of smooth muscle, a circular internal and a longitudinal external one are observed, being possible to be observed an adventitia composed of dense connective tissue not modeled. The prostate has a parenchyma can be divided into two regions, the first has its glandular alveoli supported by large amount of smooth muscle, and the second having their glandular alveoli also surrounded by muscle plain but in smaller quantities and this being supported by a dense connective tissue no modeled. The vesicular gland has a mucosa composed of a simple cubic epithelium being formed by tubules that can be straight or tortuous with secretion present inside the tubular lumen. We conclude that the male genital organs of the punare are similar macroscopically to rodent organs in general, with some differences between rodent species microscopically.
\end{abstract}

Key-words: Rodent; Male genital apparatus; Anatomy; Histology.

${ }^{1}$ Submetido em 22/03/2018 e aprovado em 24/03/2019

${ }^{2}$ Médico Veterinário; Universidade Federal da Paraíba (UFPB), Centro de Ciências Agrárias, Areia-PB, CEP: 58.397-000, E-mail: willian.medvet@hotmail.com

${ }^{3}$ Doutor em Ciências; Professor, Universidade Federal da Paraíba (UFPB), Centro de Ciências Agrárias, Programa de Pós-Graduação em Ciência Animal Areia-PB, CEP: 58.397-000, E-mail: ricardo@cca.ufpb.br

${ }^{4}$ Mestre em Ciência Animal; Estudante de Doutorando, Universidade Federal da Paraíba (UFPB), Centro de Ciências Agrárias, Programa de Pós-Graduação em Ciências Fisiológicas, Areia-PB, CEP: 58.397-000, E-mail: lucasrveter@gmail.com

${ }^{5}$ Medicina Veterinária; Universidade Federal da Paraíba (UFPB), Centro de Ciências Agrárias, Areia-PB, CEP: 58.397-000, E-mail: psicologohelder@hotmail.com

${ }^{6}$ Doutor em Ciências; Professor, Universidade Federal Rural do Semi-Árido (UFERSA), Programa de Pós-Graduação em Ciência Animal, Mossoró-RN, CEP: 59.625-900, E-mail: moacir@ufersa.edu.br 


\section{Introdução}

O punaré (Thrichomys laurentius) também conhecido como rabudo é um pequeno mamífero pertencente à ordem Rodentia, família Echimyidae, subfamília Eumysopinae de hábitos diurnos e noturnos, habitando principalmente áreas rochosas, como serrotes e lajeiros, utilizando as fendas das rochas como esconderijo, podendo ser encontrado também em áreas abertas e florestais (Moojen, 1943). No Brasil o punaré é encontrado na caatinga, cerrado, pantanal e alguns autores relatam sua presença também no Chaco paraguaio e boliviano. No nordeste brasileiro pode ser encontrado da faixa que se estende do estado do Ceará ao da Bahia (Mares e Ojeda, 1982; Mares et al., 1985; Alho et al., 1986).

O gênero Thrichomys foi descrito por Bonvicino (2008) como, de tamanho grande a médio com cauda longa, densamente pilosa e de grande fragilidade, a pelagem macia sem pelos aristiformes, na qual a coloração varia conforme a espécie. Pode-se encontrar ainda na região orbital um anel de pelos brancos, já as regiões dorsais das patas apresentam-se esbranquiçadas e com pelos ungueais claros nos dígitos.

De acordo com Teixeira et al. (2005) em estudo realizado em fêmeas das espécies $T$. pachyurus e $T$. laurentius, tais espécies apresentam período de gestação semelhante. A primeira entorno de 105 dias e a segunda com aproximadamente 95 dias de gestação. As fêmeas da primeira espécie apresentaram maturação sexual em oito semanas, sendo animais de fácil criação em cativeiro apresentando baixo percentual de confrontamento físico entre pares de acasalamento. As fêmeas de $T$. laurentius alcançam a maturidade sexual em seis semanas e as $d e T$. pachyurus em oito semanas. Os filhotes de ambas as espécies nascem precoce e comem alimentos sólidos na primeira semana de vida (Teixeira et al., 2005).

O gênero Thrichomys apresenta uma importância ecológica quanto à dispersão de sementes, mas também vem sendo apontado como reservatório de Leishmania amazonensis, uma vez que animais taxidermizados na década de 50 oriundos do estado do Ceará, foram submetidos a técnica de PCR sendo identificado o protozoário. Assim, demonstra-se sua importância quanto a seu potencial zoonótico (Cantarino, 1998).

A literatura não apresenta informações sobre a morfofisiologia do aparelho reprodutor masculino dessa espécie, fazendo-se assim, necessários mais estudos sobre essa descrição e organização do mesmo para um melhor entendimento da espécie e conservação da mesma. Este trabalho tem como objetivo estudar macroscopicamente e microscopicamente as estruturas que compõem o aparelho genital masculino do punaré, assim como, a organização celular dos mesmos, de forma a detalhar os seguintes órgãos: testículos, epidídimos, ductos deferentes, próstata e glândula vesicular.

\section{Materiais e Métodos}

O material para desenvolvimento do projeto foi proveniente do Centro de Multiplicação de Animais Silvestres - CEMAS da Universidade Federal Rural do Semi-Árido - UFERSA, Mossoró-RN, registrado junto ao IBAMA como criadouro científico sob o número 1478902.

Os animais utilizados no experimento foram adquiridos juntos a Fundação Nacional da Saúde - FUNASA em Brejinho no Rio Grande do Norte e trazidos para o Centro de Multiplicação de Animais Silvestres. Foram utilizados para realização do presente estudo, cinco machos adultos mantidos em cativeiro com peso de aproximadamente 200 gramas. Todos os animais foram eutanasiados conforme as Diretrizes de Eutanásia do Conselho Nacional de Experimentação Animal e conforme as normas da Comissão de Ética no Uso de Animais da Universidade Federal da Paraíba (UFPB), protocolo n ${ }^{\circ}$ 007/2016.

Os animais foram anestesiados com $0,025 \mathrm{mg} / \mathrm{Kg}$ de sulfato de atropina por via subcutânea e 0,2ml/Kg de Zoletil® (Zolazepam e tiletamina) por via intramuscular, sendo em seguida eutanasiados com uma injeção intracardíaca de Cloreto de Potássio 10\%.

Após a eutanásia os animais foram submetidos a uma incisão abdominal a nível da linha média, seguindo-se em direção ao prepúcio até chegar ao escroto, onde encontram-se os testículos. Todas as glândulas anexas juntamente com o pênis e os testículos foram dissecados para formar um único monobloco. 
Para procedimento histológico foram coletados fragmentos de no máximo $0,5 \mathrm{~cm}^{3} \mathrm{de}$ cada componente do aparelho reprodutor, que foram fixados em paraformoldeído a $4 \%$, ambos tamponado com fosfato de sódio $0,1 \mathrm{M}, \mathrm{pH} 7,4$ a $4^{\circ} \mathrm{C}$ por 48 horas. Após fixação o material foi submetido à metodologia de processamento histológico padrão, na qual o material foi lavado para a retirada do excesso de fixador e submetido a desidratação por meio de álcoois crescentes do 70 ao $100 \%$, depois sendo diafanizados pelo solvente orgânico xilol. Logo em seguida foi realizada a parafinização e emblocagem do material. Os blocos foram submetidos a microtomia, obtendo-se cortes de $7 \mu \mathrm{m}$ de espessura no micrótomo Leica RM 2125 RTS, sendo posteriormente levados à estufa a $55^{\circ} \mathrm{C}$. Finalmente, as lâminas foram submetidas à coloração por hematoxilina-eosina (HE). Em seguida, foi feita a montagem das lâminas, que posteriormente, foram analisadas em microscópio de luz Leica ICC $50 \mathrm{HD}$. As amostras foram processadas no Laboratório de Morfofisiologia de Animais Silvestres da Universidade Federal Rural do Semi-Árido UFERSA.

\section{Resultados e discussão}

\subsection{Macroscopia}

O punaré apresentou macroscopicamente um par de testículos encontrados no interior do saco escrotal ou da cavidade abdominal, possuindo formato ovóide, sendo revestidos respectivamente pela túnica dartos, túnica vaginal folheto parietal e visceral e pela túnica albugínea assemelhando-se ao que foi descrito aos testículos dos mamíferos por Junqueira e Carneiro (2008) e por Rodrigues et al. (2012) em estudos realizados em pacas. Juntamente aos testículos foi encontrado o epidídimo; emergindo da cauda do epidídimo foi encontrado o ducto deferente com sua disposição enovelada. A glândula vesicular foi encontrada em par com formato tubular, semelhante ao que foi descrito para capivara por Ojasti (1973). A próstata é bilobada assim como foi descrito no preá por Rodrigues et al. (2012) e semelhante ao que foi descrito em rato (Gude et al., 1982). O pênis do punaré contém um osso peniano com sua glande contendo espículas córneas, semelhante ao que foi encontrado por Menezes et al. (2003) em outros roedores como na cutia (Figura 1).

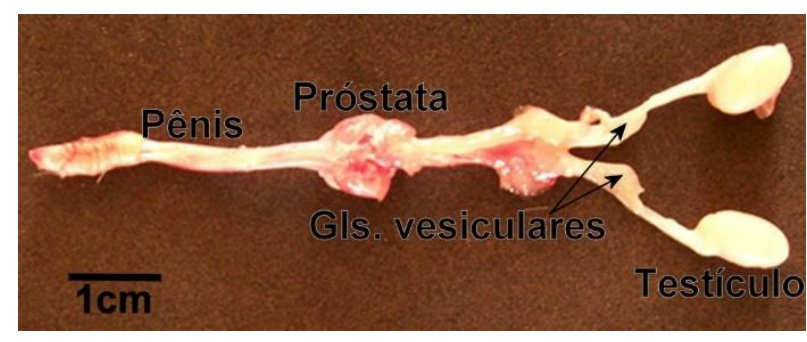

Figura 1 Imagem fotográfica do sistema reprodutor masculino do punaré (Thrichomys laurentius).

\subsection{Microscopia}

\subsubsection{Testículos}

O testículo do punaré (Thrichomys laurentius) possui túnica albugínea formada por tecido conjuntivo denso modelado, que circunda todo o testículo. As células de Sertoli encontradas nos túbulos seminíferos apresentaram forma arredondada com núcleo heterocromático pequeno e central, sendo possível a visualização da tríade nuclear, caraterística dessas células (Figura 2A, B).

Esses túbulos apoiavam-se em uma membrana basal e eram circundados externamente em toda sua extensão por células mióides com formato alongado, assim como, descrito por Junqueira e Carneiro (2008) para mamíferos de forma geral e na paca por Borges et al. (2013). Tais células apresentam atividade contrátil participando no processo de saída dos espermatozoides do lúmen tubular.

As espermatogônias eram arredondadas, núcleo heterocromático e basal com boa parte do citoplasma sendo tomada pelo mesmo. Já os espermatócitos apresentaram forma arredondada com núcleo eucromático. As espermátides puderam ser encontradas de duas formas, redonda ou alongada, estando a primeira, presente em maior número e sendo a segunda mais diferenciada em espermatozoide, estando no processo final da espermiogênese, podendo ser encontrado os corpos residuais nestas.

As células intersticiais ou células de Leydig exibiram núcleos grandes heterocromáticos tomando a maior parte do citoplasma, sendo encontradas externamente aos túbulos seminíferos na região de interstício, no espaço intertubular que ainda contém vênulas, arteríolas e nervos. 


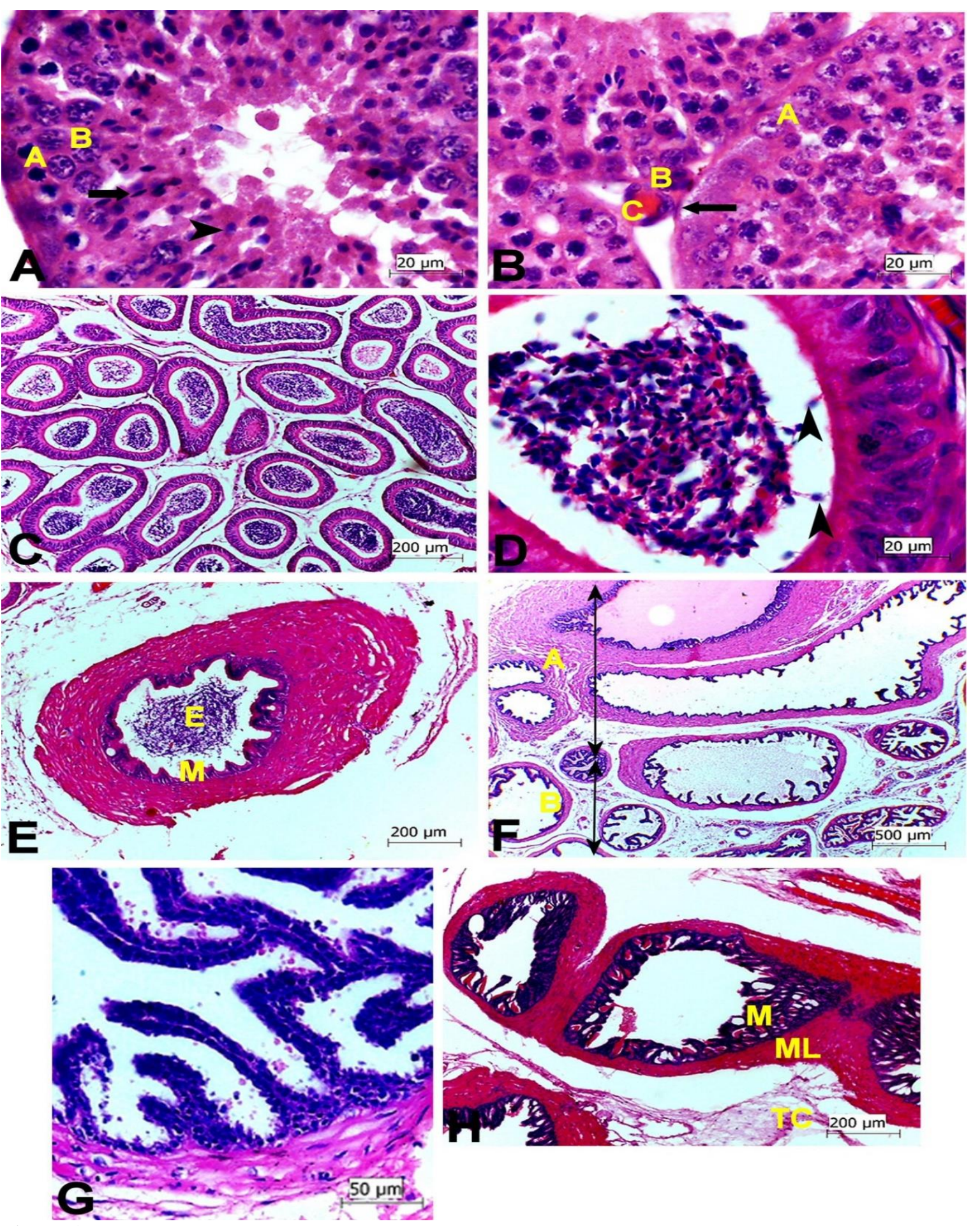

Figura 2 Fotomicrografias dos órgãos do sistema reprodutor masculino do punaré (Thrichomys laurentius). A) Lúmen do túbulo seminífero testicular. Espermatogônia (A); Espermatócito (B); Espermátide alongada (Seta); Espermátide redonda (Cabeça de seta). B) Intestício entre túbulos seminíferos. Célula de Sertoli (A); Célula de Leydig (B); Célula mióide (Seta); Arteríola (C). C) Corte transversal dos túbulos epididimários. Observar no seu interior a massa espermática. D) Epitélio pseudoestratificado com estereocílio (pontas de seta) do epidídimo com espermatozóides no lúmen. E) Corte transversal do duto deferente com mucosa pregueada (M); Espermatozóide (E). F) Próstata com alvéolos glandulares apoiados em grande quantidade de músculo liso (A); alvéolos glandulares circundados por menor quantidade de músculo liso (B). G) Dobras glandulares da próstata com epitélio cúbico simples. H) Glândula vesicular com mucosa pregueada (M); Músculo liso (ML); Tecido conjuntivo denso não-modelado (TC). Coloração de hematoxilina-eosina.

Revista Agropecuária Técnica, Areia-PB, v. 39, n. 4, p. 308-315, 2018

DOI: $10.25066 /$ agrotec.v39i4.38738 
Estudos realizados em roedores demonstraram que o testículo dos animais dessa ordem é composto basicamente por um conjunto de túbulos seminíferos contorcidos com a presença de um epitélio germinativo com células de Sertoli, e os vários tipos celulares encontrados no processo espermatogênico, com presença de um tecido conjuntivo frouxo entre os túbulos, além das células de Leydig no intestísio. Da mesma forma, descrevem que no testículo pode ser observado uma camada de tecido conjuntivo denso modelado constituindo a túnica albugínea, além de vasos e nervos presentes no interstício (Gude et al., 1982; Sprando et al., 1999), corroborando o presente estudo. Os testículos do punaré se assemelham morfologicamente aos das demais espécies de roedores tanto na localização macroscópica, sintopia e organização celular.3.2.2 Epidídimo

O epidídimo apresentou seus túbulos epididimários compostos por um epitélio pseudoestratificado com estereocílios, composto por células basais e prismáticas apoiadas em uma lâmina basal, estando circundados por músculo liso, sendo que na região da cabeça do epidídimo, os estereocílios eram menores em relação às demais áreas (corpo e cauda). Os túbulos estavam separados entre si por tecido conjuntivo denso não-modelado (Figura 2C, D).

Autores encontram resultados semelhantes em estudos com epidídimos de outros roedores, sendo na maioria dividido em três regiões: cabeça, corpo e cauda, todos compostos por ductos epididimários apresentando um epitélio pseudoestratificado com estereocílios com células principais e basais que não alcançam o lúmen tubular, variando entre as regiões, o tamanho dos estereocílios (Nicander e Glover, 1973; Hoffer e Greenberg, 1978; Abe et al., 1982; Borges et al., 2013). Diferentemente do punaré, um epitélio prismático simples na cauda do epidídimo foi descrito em preá, cutia e rato gigante da índia (Amiya e Maiti, 1982; Menezes et al., 2003; Santos et al., 2012).

Segundo Matamoros (1981) o epitélio epididimário da paca altera-se de pseudoestratificado para prismático simples conforme se aproxima da cauda do epidídimo, diferentemente do encontrado por Borges et al. (2013) que descreve que o epitélio ao se aproximar da cauda torna-se cúbico simples. No punaré todas as regiões do epidídimo apresentaram epitélio pseudoestratificado.

\subsubsection{Ducto deferente}

$\mathrm{O}$ ducto deferente apresentou uma mucosa pregueada formada por um tecido epitelial pseudoestratificado formado por células basais e principais com estereocílios, sendo rico em fibras elásticas. Este epitélio está apoiado em uma lâmina basal estando em seguida acompanhado por dois feixes de músculo liso, um interno em disposição circular e outro externo em sentido longitudinal, e ainda uma adventícia composta por tecido conjuntivo denso não-modelado (Figura 2E). O lúmen apresentouse com espermatozóides em seu interior, semelhante ao descrito em rato de areia (Sprando et al., 1999) e em preá (Santos et al., 2012).

O epitélio descrito é o mesmo encontrado em rato (Hoffer e Greenberg, 1978), entretanto, diferente da descrição do epitélio na paca, na qual o epitélio seria estratificado prismático com estereocílios (Borges et al., 2013). Amiya \& Maiti (1982) descrevem ainda que o epitélio do ducto deferente do rato gigante da índia também é composto por um epitélio pseudoestratificado com estereocílios proeminentes.

Igualmente ao encontrado no punaré, a camada muscular do epidídimo também é descrita como composta por feixes longitudinais e circulares em porquinho da índia (Hoffer e Greenberg 1978), porém Gude et al. (1982), descreve tal camada em rato de laboratório como contendo três feixes, ao invés de duas, a primeira interna longitudinal a média circular e a externa longitudinal. Tal autor cita nesta espécie, assim como no punaré, um epitélio pseudoestratificado, com mucosa pregueada.

\subsubsection{Próstata}

A próstata apresentou-se com parênquima que pode ser dividido em duas regiões, a primeira possui seus alvéolos glandulares apoiados em grande quantidade de músculo liso, e a segunda tendo seus alvéolos glandulares circundados também por músculo liso só que em menor quantidade, estando apoiado em um tecido conjuntivo denso não-modelado (Figura $2 \mathrm{~F}, \mathrm{G})$. Na primeira região pode ser observado os alvéolos glandulares com um lúmen maior do que aqueles encontrados na região com predominância de tecido conjuntivo, em 
compensação essa última apresentou seus alvéolos com uma mucosa mais pregueada do que a primeira, estando também nessa região a maior parte da irrigação da glândula. A mucosa era formada por um epitélio cúbico simples apoiado em uma lâmina basal.

No rato de laboratório, a próstata é dividida em lobos dorsal e ventral rodeada por músculo liso (Gude et al., 1982), semelhante ao que foi encontrado no punaré. No rato de areia, a próstata apresenta-se dividida em dois lobos um dorsal e um ventral, onde neste primeiro o epitélio é cúbico simples e na segunda, prismático simples (Sprando et al., 1999). De acordo com Cagnon et al. (2000), a próstata ventral do rato apresenta uma organização glandular do tipo túbulo-alveolar com mucosa pregueada formada por um epitélio cúbico simples e variáveis tamanhos de ácinos, sendo estes ainda rodeados por músculo liso e tecido conjuntivo. A próstata do punaré apresentou mucosa pregueada composta por um epitélio cúbico simples diferindo do epitélio pseudoestratificado encontrado em cutia (Menezes et al., 2010), preá (Santos et al., 2012) e rato de laboratório (Hebel \& Stromberg, 1986).

A próstata do rato gigante da índia é dividida em lobos dorsal, ventral e lateral diferentemente do encontrado no punaré. No primeiro lobo são observados ácinos periféricos e centrais com variação em relação as suas dobras epiteliais, o lobo dorsal também contém uma camada fibromuscular maior em relação ao lobo ventral, sendo este semelhante ao lateral (Amiya \& Maiti, 1982).

\subsubsection{Glândula vesicular}

A glândula vesicular apresentou sua mucosa bem pregueada formada por um epitélio cúbico simples apoiado em uma lâmina basal que em seguida une-se a uma camada de músculo liso e seu interstício estando formado por um tecido conjuntivo denso não-modelado. A glândula vesicular era formada por túbulos com secreção presente no interior do lúmen tubular (Figura $2 \mathrm{H})$.

A glândula vesicular do rato gigante da índia possui uma cápsula fibromuscular com uma mucosa composta por um epitélio colunar simples com poucas dobras na região proximal (Amiya \& Maiti, 1982), diferindo dos resultados encontrados no punaré.
$\mathrm{O}$ rato possui as glândulas vesiculares lobuladas e grandes (Greene, 1963). Segundo Ojasti (1973), a glândula vesicular da capivara está organizada em par, com formato tubular, situada dorsalmente à bexiga desembocando na parte dorsal da uretra. De acordo com Cooper e Schiller (1975), o porquinho da índia apresenta glândulas vesiculares localizadas dorsais à vesícula urinária unindo-se a uretra por um par de tubos sendo cilíndricos, alongados e tubulares. Estudando a glândula vesicular do rato, Gude et al. (1982), observou que esta contém uma mucosa composta por células epiteliais colunares e bem pregueada. Já para Hebel \& Stromberg (1986), a mucosa da glândula vesicular do rato de laboratório é formada por um epitélio contendo células prismáticas e basais (pseudoestratificado) diferindo do epitélio encontrado na glândula do punaré, mas, assemelhando-se ao que foi descrito no preá, cutia, rato de areia, paca, rato (Matamoros, 1981; Gude et al., 1982; Sprando et al., 1999; Menezes et al., 2010; Santos et al., 2012).

\section{Conclusão}

O punaré possui anexo ao seu sistema reprodutor masculino dois testículos, dois epidídimos, dois ductos deferentes, duas glândulas vesiculares e uma próstata bilobada que se assemelham à maioria dos roedores. Entretanto, macroscopicamente a próstata diferiu da encontrada no rato gigante da índia, e microscopicamente, o epidídimo apresentou diferenças em relação ao preá, cutia e rato gigante da índia, o ducto deferente apresentou diferenças para o da paca e do rato de laboratório, a próstata apresentou diferenças para o de cutia, preá e rato de laboratório e a glândula vesicular apresentou diferenças para a de rato de laboratório e rato gigante da índia.

\section{Referências}

Abe, K.; Takano, H.; Ito, T. Response of the epididymal duct in the corpus epididymis to efferent of epididymal duct ligation in the mouse. Journal of Reproduction and Fertility, v.64, n.1, p.69-71, 1982. https://doi.org/10.1530/jrf.0.0640069

Amiya, P. S. H.; Maiti, B. R. Quantitative studies of the accessory reproductive organs of the male bandicoot rat $-\mathrm{A}$ common rodent 
pest. Anatomischer Anzeiger, v.151, n.5, p.483-495, 1982.

https://www.ncbi.nlm.nih.gov/pubmed/7137576

Alho, C. J. R.; Pereira, L. A.; Paula, A. C. Patterns of habitat utilization by small mammal populations in Cerrado Biome of Central Brazil. Mammalia, v.50, n.4, p.447-460, 1986. https://doi.org/10.1515/mamm.1986.50.4.447

Bonvicino, C. R.; Oliveira, J. A.; D`andrea, P. S. Guia dos roedores do Brasil, com chaves para gêneros baseadas em caracteres externos. Rio de Janeiro: Centro PanAmericano de febre aftosa - OPAS/OMS, 2008.

$120 \mathrm{p}$.

https://s3.amazonaws.com/academia.edu.documents/3726 0445/Guia-dos-Roedores-do-

Brasil.pdf?AWSAccessKeyId=AKIAIWOWYYGZ2Y53 UL3A\&Expires $=1553627529 \&$ Signature $=$ ZDhEoUVTeV \%2BFk3\%2BKS593QaWgPKE\%3D\&response-contentdisposition=inline\%3B\%20filename\%3DGuia_dos_roedo res_do_brasil.pdf

Borges, E. M.; Branco, E.; Lima, A. R.; Leal, L. M.; Martins, L. L.; Reis, A. C.; Cruz, C.; Machado, M. R. F.; Miglino, M. A. Morfologia e topografia dos órgãos genitais masculinos externos da paca (Cuniculus paca, Linnaeus, 1766). Biotemas, v.26, n.4, p.211-222, 2013. https://doi.org/10.5007/2175-7925.2013v26n4p209

Cagnon, V. H. A.; Camargo, A. M.; Rosa, R. M.; Fabiani, R.; Padovani, C. R.; Martinez, F. E. Ultrastructure study of the ventral lobe of the prostate of mice with streptozotocin induced diabetes (C57BL/6J). Tissue \& Cell, v.32, n.4, p.275-283,

2000 .

https://doi.org/10.1002/ar.1091900304

Cantarino, C. L. M. Leishmaniose tegumentar americana: uso de técnicas da biologia molecular no diagnóstico de infecção de roedores de coleção do Museu Nacional UFRJ. 1998. 70 f. (Dissertação de Mestrado) Fundação Oswaldo Cruz, Escola Nacional de Saúde Pública, Rio de Janeiro, 1998. https://www.arca.fiocruz.br/handle/icict/5136

Cooper, G.; Schiller, A. L. Anatomy of the guinea pig. Cambridge, Mass.: Havard University Press, 1975, 417p. http://agris.fao.org/agrissearch/search.do?recordID=US201300526352

Greene, E. C. Anatomy of the rat. Philadelphia: American Philosophical Society, v.1, p.370, 1963.

https://www.cabdirect.org/cabdirect/abstract/1956140541 $\underline{6}$
Gude, W. D.; Cosgrove, G. E., Hirsch, G. P. Histological atlas of the laboratory mouse. New York: Plenum Press, p.70-79, 1982. https://books.google.com.br/books?hl=en\&lr=\&id=9rwG CAAAQBAJ\&oi=fnd\&pg=PA4\&dq=Gude, + W. + D..,$+\%$ 3B+Cosgrove, + G. + E., + Hirsch, + G. + P.+Histological+atlas +of+the+laboratory+mouse\&ots=Eahq29k7U5\&sig=M7d yCA-

xGTKnfeueslCXrzXOI88\&redir esc=y\#v=onepage\&q\&f =false

Hebel, R.; Stromberg, M. V. Anatomy and embryology of the laboratory rat. Wörthesee: BioMed Verlag, 1986. 270p. https://www.agris.fao.org/agrissearch/search.do?recordID=US201300434037

Hoffer, A. P.; Greenberg, J. The structure of the epididymis, efferent ductules and ductus deferens of the guinea pig: A light microscopia study. The Anatomical Record, v.190, n.3, p.659-678, 1978. https://doi.org/10.1002/ar.1091900304

Junqueira, L. C.; Carneiro, J. Aparelho reprodutor masculino. In: JUNQUEIRA, L. C.; CARNEIRO, J. Histologia básica. Rio de Janeiro: Editora Guanabara, v21, p.323-334, 2008.

Mares, M. A.; Ojeda, R. A. Patterns of diversitu and adaptaion in South American hystricognath rodents. In: Mares, M.A.; Genoways, H.H. (Ed.). Mammalian biology in South America: a symposium held at the Pymatuning Laboratory of Ecology, May 1014, 1981. Linesville: Pymatuning Laboratory of Ecology, University of Pittsburgh, v.6, p.393-432, 1982.

Mares, M. A.; Willig, M. R.; Lacher, T. E. The Brazilian Caatinga in South American zoogeography: tropical mammals in a dry region. Journal of Biogeograph, v.12, n.1, p.57-69, 1985. https://www.jstor.org/stable/2845029

Matamoros, Y. Anatomia e histologia dei sistema reproductor dei tepezcuinte (Cuniculus paca). Revista de Biologia Tropical, v.29, n.1, p.155-164, 1981. https://revistas.ucr.ac.cr/index.php/rbt/article/view/25534

Menezes, D. J. A.; Carvalho, M. A. M.; Assis, Neto A. C.; Oliveira, M. F.; Farias, E. C.; Miglino, M. A.; Medeiros, G. X. Morfologia dos órgãos genitais externos do macho de cutia (Dasyprocta aguti Linnaeus, 1766). Brazilian Journal of Veterinary Research Animal 
Sciense, v.40, n.2, p.148-153, 2003. https://www.scielo.br/pdf/\%0D/bjvras/v40s2/25953.pdf

Menezes, D. J. A.; Assis Neto, A. C.; Oliveira, M. F.; Miglino, M. A.; Pereira, G. R.; Ambrósio, C. E.; Ferraz, M. S.; Carvalho, M. A. M. Morphology of the male agouti accessory genital glands (Dasyprocta prymnolophaWagler, 1831). Pesquisa Veterinária Brasileira, v.30, n.9, p.793-797, 2010.

http://www.scielo.br/pdf/\%0D/bjuras/v40s2/25953.pdf

Moojen, J. Alguns mamíferos colecionados no nordeste do Brasil com a descrição de duas espécies novas e notas de campo. Boletim do Museu Nacional, v.1, p.1-19, 1943.

Nicander, L.; Glover, T. D. Regional histology and fine structure of the epididymal duct in the golden hamster (Mesocricetus auratus). Journal of Anatomy, v.114, n.3, p.347-364, 1973.

https://www.ncbi.nlm.nih.gov/pmc/articles/PMC1271449 /pdf/janat00317-0027.pdf

Ojasti, J. Estudio biológico del Chigüira o Capibara. Caracas: Ediciones del Fondo Nacional de Investigaciones Agropecuárias, 1973. 275p.

Rodrigues, M. N.; Oliveira, G. B.; Albuquerque, J. F. G.; Menezes, D. J. A.; Neto, A. C. A.; Miglino, M. A.; Oliveira, M. F. Aspectos anatômicos do aparelho genital masculino de preás adultos (Galea spixii Wagler, 1831). Biotemas, v.26, n.1, p.181-188, 2012. https://doi.org/10.5007/2175-7925.2013v26n1p181

Santos, P. R. S.; Oliveira, M. F.; Silva, A. R.; Camargo, C. M. O. N.; Antônio, C.; Assis Neto, A. C. A. A microestrutura e o desenvolvimento dos órgãos genitais masculinos de preás (Galea spixii) criados em cativeiro. Pesquisa Veterinária Brasileira, v.32, n.1, p.84-90, 2012. http://dx.doi.org/10.1590/S0100-736X2012001300015

Sprando, R. L.; Collins, T. F. X.; Black, T. N.; Olejnik, N.; Rorie, J. L.; West, L. J.; Bowers, J. D.; Sass, N.; Robl, M. Light microscopic observations on the reproductive tract of the male sand rat, Psammomys obesus. Tissue and Cell, v.31, n.1, p.99-115, 1999. https://doi.org/10.1054/tice.1999.0003

Teixeira, B. R.; Roque, A. L. R.; Barreiros Gómez, S. C.; Borodin, P. M.; , A. M.; D'andrea, P. S. Maintenance and breeding of Thrichomys (Trouessart, 1880) (Rodentia: Echimyidae) in captivity. Memórias do Instituto Oswaldo Cruz, v.100, n.6, p.627630, 2005. http://dx.doi.org/10.1590/S0074$\underline{02762005000600005}$ 